\title{
Evaluation of the Black Cumin Seed Oil Role (BCSO) on a Decline in eNOS Expression and Plasma NO Levels: Initial Studies Kemopreventive BCSO for Lung Cancer
}

\author{
Titiek Hidayati ${ }^{*}$, Akrom $^{2}$, Indrayanti ${ }^{3}$, Sagiran $^{4}$ \\ ${ }^{1}$ Departement of Epidemiology, Community and Family Medicine, Medical and Health Science Faculty, \\ Universitas Muhammadiyah Yogyakarta, Ring Road Barat, Tamantirto, Bantul, Yogyakarta, Indonesia. \\ 2 Departement of Farmacology and Clinical Pharmacy, Prof Supomo Street, Janturan, Umbul harjo, \\ Yogyakarta, Indonesia. \\ ${ }^{3}$ Departement of Patology Anatomi, Medical and Health Science Faculty, Universitas Muhammadiyah \\ Yogyakarta, Ring Road Barat, Tamantirto, Bantul, Yogyakarta, Indonesia. \\ ${ }^{4}$ Departement of Surgery, Medical and Health Science Faculty, Universitas Muhammadiyah Yogyakarta, Ring \\ Road Barat, Tamantirto, Bantul, Yogyakarta, Indonesia. \\ ${ }^{*}$ Corresponding author. Tel.: +62817904942; email: hidayatifkumy@yahoo.co.id \\ Manuscript submitted February 10, 2017; accepted April 19, 2017. \\ doi: 10.17706/ijbbb.2017.7.3.162-168
}

\begin{abstract}
BCSO is effective as an anti-aging agent in cultures of endothelial and macrophage exposed 7.12, dimethyl-benzantracene (DMBA). Reactive radicals damage endothelial tissue, cause inflammatory reactions and have a role in carcinogenesis. Excessive eNOS expression linked to chronic inflammation and carcinogenesis of lung cancer. The research objective was to determine the effect of BCSO on the expression of eNOS and NO levels of macrophage SD rats exposed DMBA.

A study used 36 rats SD that divided into 6 groups, given BCSO $(0,01,0,05$ and $0.1 \mathrm{ml} /$ day), positive, negative and normal control. Variables were serum levels of NO and eNOS expression in endothelial tissue.

The results showed that eNOS expression in DMBA group is higher than the normal group $(\mathrm{P}<0.05)$. BCSO will decrease eNOS expression and NO levels. ENOS expression and NO levels in group BCSO 0,01 and $0,05 \mathrm{ml} / \mathrm{kg}$ body weight / day lower than the DMBA group $(\mathrm{p}<0.05)$, and similar to the normal group (P> 0.05). Conclusion: a dose BCSO can degrade endothelial eNOS expression and NO levels of macrophage culture supernatant SD rat DMBA induced.
\end{abstract}

Key words: Antiaging, black cumin seed oil, degenerative diseases, the prevention of cardiovascular disease.

\section{Introduction}

The endogenous antioxidant system involved Nrf2 as a transcription factor and endothelial nitric oxide syntase (eNOS) [1]. ENOS enzyme, nitric oxide (NO) and reactive oxygen species (ROS) has a role in regulating the function and structure of blood vessels including the angiogenesis [2]. Endothelial cells produce nitric oxide (NO). Nitric oxide (NO) in vivo increases in carcinoma angiogenesis [3]-[5].

Exposure to reactive radicals, such as 7.12, dimethylbenzantracene (DMBA), increased eNOS expression and NO production [6]-[8]. Overexpression eNOS linked to chronic inflammation and carcinogenesis [9]-[11]. Antioxidative and antiangiogenesis compounds inhibit carcinogenesis [9], [12].

Black cumin seed oil contains unsaturated fatty linoleic and linolenic, thymoquinone, nigelon and nigelin 
that are antioxidative [13], [14]. Thymoquinone is a powerful antioxidant, chemo preventive and immunomodulators [15]-[19]. Giving BCSO before and during DMBA induced in SD rats will inhibit mammary carcinogenesis carcinoma [1]. BCSO chemo preventive mechanisms have been demonstrated where BCSO will inhibit the cyclooxygenase pathway and a 5-lipooksigenase through inflammatory reaction barrier [20], [21].

BCSO chemo preventive mechanisms through eNOS and NO is still uncertain, whereas NO is pleiotropic. The research objective was to determine the effect on the expression of eNOS BCSO and the levels of NO in macrophage cell culture supernatant SD rat DMBA induced.

\section{Method}

An experimental study in vivo on 36 rats SD who were divided into 6 groups, given MBJH 3 ratings dose (0:01, 0:05 and $0.1 \mathrm{ml} /$ day), vitamin E (positive control), and induced DMBA, except normal control (without induced DMBA),

Parameters measured were culture supernatant NO levels of eNOS expression in macrophages and endothelial tissue. Experts conduct examination of the expression of eNOS done immuno histo chemical.

\subsection{Work Procedures}

1) Animal testing quarantined and acclimatized. Forty SD strain rats aged 2 weeks included in the plastic enclosure covered with woven wire. Rats are adapted for 1 week at home maintenance before being used for research. Test animals fed and watered in accordance standards for quarantine and acclimation. Acclimatization test animals were randomly divided into six groups on the sixth day [1].

2) The provision of treatment and DMBA induction.

36 SD strain rats aged 3 weeks were divided into six groups, each of 6 animals after they were randomized. Then, the mice housed in a plastic enclosure that is covered with woven wire. Mice were weighed weekly during the study to determine the weight development. Group I is the normal group. Animal testing in this group was not given treatment. Pets only get to eat and drink during the testing standards. Groups II, III and IV of the treatment groups. Animal tests get BCSO doses of 0.01, 0.05 and $0.1 \mathrm{ml}$ / kg. Animal testing DMBA induced single dose of $15 \mathrm{mg} /$ head. Group V is a negative control group. Group VI was the positive control group. The group get vitamin E / A or tocopherol and get a single dose of DMBA induction.

3) Observations expression of eNOS

Aorta was isolated. Aortae located at the back of the chest, above the heart. Aortae taken from the chest cavity after the peritoneum is opened, and after the mice anesthesia with chloroform. Aortae histopathological examination conducted as researchers previously with the same procedure, namely the procedure process of the network, with Hematoxillin \& eosin staining and analysis of the results of histopathologic assessment. Most stocks do endothelial tissue histology staining with antibodies immuno histo chemical eNOS. Painting immuno histo chemical carried out according to standard procedures in anatomical pathology laboratory, medical faculty of the University of Gadjah Mada [1]. Mixture paintwork immuno histo chemical read by doctors Expert Pathology in the Faculty.

Macrophages isolation procedures performed according previous studies [1]. Mice were placed in the supine position, the skin of the abdomen is opened and cleaned sheath peritoneum with $70 \%$ alcohol, then injected $10 \mathrm{ml}$ cold RPMI medium into the peritoneal cavity, wait for 3 minutes as he rocked slowly. Peritoneal fluid is removed from the peritoneal cavity by tapping with two fingers in the cavity, the fluid aspirated with a syringe injection, selected in the lean and away from the gut. Aspirates centrifuged at 1200 $\mathrm{RPM}, 4^{\circ} \mathrm{C}$ for 10 minutes. The supernatant was discarded, the pellets resuspended in RPMI containing $10 \%$ FCS. 
The number of cells counted by hemocytometer, then added a complete medium to obtain a cell suspension with a density of $1 \times 106 / \mathrm{ml}$. Macrophage cell counting procedures conducted according the general procedure. Object alcoholic glass cleaned with a tissue, then the object mounted on the tool according to the size of the place. Fluid macrophages stirred, then put the liquid in a sterile tube and pipetted into a tool in the tool hemocytometer then read interval microscope. The number of macrophages is calculated by cell counting with a magnification of 100 times. Cell count is performed to determine the number of macrophage cells contained in the cell suspension.

Micro cultures suspension cells grown in 24 wells that have been given a round coverslips. Each of the wells filled in 200 microliters $\left(2 \times 105\right.$ cells). Cells were incubated in a 5\% CO2 incubator, $37^{\circ} \mathrm{C}$ for 30 minutes. Cell added a complete medium of $1 \mathrm{ml}$ each of the wells and incubated 2 hours. Cells were washed 2 times with RPMI $1 \mathrm{ml}$ each of the wells and cells were incubated in complete medium for up to 24 hours [21].

Macrophage culture supernatant was collected in wells plate 36 is checked by the method Gries. 0.1 grams of N- (1-naphthyl) ethylenediamine hydrochloride (Sigma N 5889) was dissolved in $100 \mathrm{~mL}$ of distilled water to make a solution of Griess A. The solution was stored at $0-4{ }^{\circ} \mathrm{C}$ and protected from light. Griess B solution consisting of 1 gram sulfanilamide (Sigma S9251) were dissolved in $100 \mathrm{~mL}$ of 5\% (v / v) orthophosphoric acid. The solution was stored at $0-4{ }^{\circ} \mathrm{C}$ and protected from light. $10 \mathrm{mM}$ solution of nitric standard prepared by the following procedure: $69.0 \mathrm{mg}$ sodium nitrate dissolved in $100 \mathrm{~mL}$ of distilled water. The solution is stored at $0-4{ }^{\circ} \mathrm{C}$, protected from light. The test measures the sample is as follows: 100 $\mathrm{uL}$ of sample and standard nitrite included in a 24 -well microliter plate. If the sample is less than $100 \mathrm{uL}$, the volume is increased to $100 \mathrm{uL}$ with water or medium. Samples are then added $100 \mathrm{uL}$ Griess solution and incubated at room temperature for 15 minutes until it changes color. All samples and standards put in a microliter plate, and then ELISA reader measured absorbance. Absorbance measurement for a standard sample and performed at a wavelength of $540 \mathrm{~nm}$.

\subsection{Data Analysis}

Statistical methods are used depending on the type of analysis weight development Data were analyzed by Anova. The analysis followed by Turkey's test to analyze the significance difference in the average value of inter-group and inter-time data retrieval. Histopathology differences were analyzed by descriptive and inference (analytic). Statistical testing used ANOVA test to determine differences in the average number of gene expression, and levels between groups $(\mathrm{p}<0.05)$, followed by multiple test comparison. ENOS expression data expressed as a percentage of endothelial cell expression. eNOS expression data and NO levels of macrophage culture supernatant tested the mean difference between groups with a confidence level of 95\%. Immuno histo chemical picture presented descriptively.

\section{Result}

\subsection{Endothelial eNOS Expression}

Test results immuno histo chemical eNOS expression of endothelial tissue SD rat DMBA induced after administration BCSO presented in Table 1.

The results showed that the DMBA induced significantly increased the expression of eNOS. ENOS expression in DMBA group is higher than in the normal group $(\mathrm{P}<0.05)$. Award BCSO decreased the expression of eNOS. ENOS expression in group BCSO 0:01 and 0:05 ml / kg body weight / day lower than the DMBA group $(\mathrm{p}<0.05)$, and no different from the normal group $(\mathrm{P}>0.05)$. ENOS expression in group BCSO $0.1 \mathrm{ml} / \mathrm{kg} /$ day did not differ with DMBA group and higher than the normal group $(\mathrm{p}<0.05)$. eNOS expression vitamin E group (positive control) did not differ with different groups of DMBA and the normal 
group $(p<0.05)$.

Table 1. eNOS Expression of Endothelial Tissue SD Rats Induced with DMBA after Getting BCSO Percentage of Endothelial eNOS Expression (\%)

\begin{tabular}{ccccc}
\hline \hline Group & $\mathrm{N}$ & The mean expression of eNOS & P1 & P2 \\
\hline $\begin{array}{c}\text { normal control } \\
\text { DCSO }\end{array}$ & 6 & $12.78 \pm 9.83$ & & 0.001 \\
$\begin{array}{c}\text { DMBA treatment }+0.01 \mathrm{ml} / \mathrm{KgBW} \\
\text { DMBA treatment }+0.05 \mathrm{ml} / \mathrm{KgBW} \\
\text { BCSO }\end{array}$ & 6 & $13.88 \pm 4.95$ & 0.85 & 0.001 \\
$\begin{array}{c}\text { DMBA Treatment + 0.1 ml / KgBW } \\
\text { BCSO }\end{array}$ & 6 & $19.06 \pm 7.11$ & 0.33 & 0.002 \\
$\begin{array}{c}\text { Negative control DMBA } \\
\text { Positive control (DMBA + Vitamin } \\
\text { E) }\end{array}$ & 4 & $25.68 \pm 11.31$ & 0.04 & -0.001 \\
\hline
\end{tabular}

$\mathrm{P} 1=$ different test to the normal control group

$\mathrm{P} 2=$ different test against the negative control group

\subsection{NO Levels in the Culture Supernatant of Macrophages}

The observation of the levels of NO in macrophage culture supernatant SD rat DMBA induced presented in Table 2.

Table 2. Levels of NO in Macrophage Culture Supernatant SD Rat DMBA Induced after Administration BCSO

\begin{tabular}{ccccc} 
Group & N & NO levels (mean \pm SD) (moll / ml) & P1 & P2 \\
Normal Control & 6 & $0.27 \pm 0.09$ & - & 0.01 \\
Treatment of 0.01 ml / KgBW BCSO & 6 & $0.29 \pm 0.10$ & 0.77 & 001 \\
Treatment of 0.05 ml / KgBW BCSO & 5 & $0.22 \pm 0.06$ & 0.98 & 0.000 \\
Treatment of 0.1 ml / KgBW BCSO & 6 & $0.29 \pm 0.15$ & 0.77 & 0.002 \\
Negative control DMBA & 4 & $0.58 \pm 0.18$ & 0.001 & - \\
Positive Control (tocopherol) & 6 & $0.48 \pm 0.14$ & 0.005 & 0.22 \\
\hline \hline
\end{tabular}

$\mathrm{P} 1=$ different test to the normal control group

$\mathrm{P} 2$ = different test against the negative control group

The results showed that the potential increase DMBA induced NO production by macrophages. Based on the Table 2, the levels of NO in macrophage culture supernatant SD rat DMBA group was higher than normal levels of NO control group, but not statistically significant $(p<0.05)$. NO levels in the culture supernatant of macrophages, BCSO low-dose group (0:01 and 0:05 ml / kg) lower than in the DMBA group $(p<0.05)$.

\section{Discussion}

Three isoforms of nitric oxide synthase (NOS) have been identified, namely endothelial NOS, neuronal NOS, and inducible NOS (iNOS). Although iNOS has been widely studied in the mechanism of carcinogenesis is exposed to carcinogens DMBA, yet eNOS test has not been performed. iNOS is an enzyme regulator of NO production in macrophages, whereas eNOS is the regulator of NO production in endothelial cells. The results showed exposure to DMBA would increase eNOS expression rat endothelial cells and NO production by macrophages.

The results of the study in accordance with previous studies [11] have shown that increased expression of iNOS in the group that accompanied DMBA-induced mammary carcinogenesis tissue or tissues of the mouth. Other researchers have also proved that the DMBA induced serum NO level will enhance and increase carcinogenesis [22]. Giving BCSO shown to decrease serum levels of NO and reduce the risk of mammary cancer incidence [1]. 
Results of in vivo study is also consistent results of epidemiological studies in which patients who have genetic polymorphisms of eNOS that had higher levels of NO lower than patients who did not undergo genetic polymorphisms of eNOS, also has a quality of life and the success of therapy was higher [23]. Previous research has shown that the compound has potential chemo preventive BCSO or anticancer. [1] proved that the hexane extract BCSO inhibit mammary carcinogenesis in rats induced SD DMBA. In 2004, [16] proved that BCSO ethanol extract inhibits the formation of mammary cancer. [24] demonstrated the effects anti clastogenic thymoquinone. In 2001, [25] proving that thymoquinone a chemo preventive for gastric cancer in rats induced by DMBA. In 1999, [26] also been proved that thymoquinone have anti fibrosarcoma.

Ignarro, 2010 [4] and Yuk-Kwan et all, 2002 [7] states that NO compounds have pleiotropic effects. At low doses, NO has a function as a vasodilator and cellular signaling, keeping the body homeostasis and angiogenesis and anti-infective. Though in large doses, Compound NO, has potential as a source of reactive radicals and destabilize the genetic [17], [19], [20]. Genetic changes due to oxidative stress genes proto-oncogene are beginning the process of carcinogenesis. Giving anti-inflammatory antioxidant compounds will inhibit the process of carcinogenesis [5]. Antioxidant compounds are inhibitors of eNOS expression that NO production is not abundant. This demonstrates the ability to decrease the incidence of cancers such as compound BCSO, thymoquinone [21]-[23]. Another mechanism of carcinogenesis in a compound suspected of NO through a mechanism immunosuppressants. NO abundant compounds have proven to be had imunopresan effect on lymphocytes. Effects of immunosuppressant will inhibit lymphocyte proliferation and diferensi thus decreasing the amount CD4Th which plays an important role as imunosurveilan cancer [18].

\section{Conclusion}

BCSO 0,01 and 0,05 ml / kg / day can decrease endothelial eNOS expression and NO levels of macrophage culture supernatant SD rat DMBA induced..

\section{Acknowledgment}

First author wish to thank Indonesian Ministry of higher education (Indonesia DIKTI). A 2017 Competitive Grant Program, Penelitian Unggulan Perguruan Tinggi (PUPT) / Leading Research Universities 025/E3/2017 from Indonesia DIKTI supported this work.

\section{References}

[1] Akrom. (2013). The Mechanism Kemopreventif BCSO hexane extract in DMBA-induced SD rats: Study of Antioxidants and immunomodulators. Dissertation, Doctoral Program in Medical and Health Sciences Faculty, Yogyakarta

[2] Chen, Y., Zhang, S., Peng, G., Yu, J., Liu, T., Meng, R., Li, Z., Zhao, Y., \& Wu, G. (2013). Endothelial NO synthase and reactive oxygen species mediated effect of simvastatin on vessel structure and function: pleiotropic and dose-dependent effect on tumor vascular stabilization. Int J Oncol., 42(4), 1325-1336.

[3] Galley, H. F., \& Webster, N. R. (2004). Physiology of the Endothelium. British Journal of Anaesthesia, 93(1), 105-113.

[4] Ignarro, L. J. (2010). Nitric Oxide, Biology and Pathobiology, 2nd edition. Academic Press, California, USA.

[5] Mei, K., Cai, X. H., Du, L., Chen, Y. F., Huang, S., Chen, J., Yin, X. D., Zhang, Z. X., Zhao, X., Zhou, C. Y., Yu, J. R. (2010). Effect of nitric oxide derived from endothelial nitric oxide synthase on tumor angiogenesis. Chin J Cancer, 29(1), 32-37. 
[6] Arora, A, Siddiqui, I. A., \& Shukla, Y. (2004). Modulation of p53 in 7,12-dimethylbenz[a]anthracene -induced skin tumors by diallyl sulfide in Swiss albino mice. Mol Cancer Ther., 3(11), 1459-66.

[7] Min, L., et al. (2002). The mRNA expression of inducible nitric oxide synthase in DMBA-induced hamster buccal-pouch carcinomas: an in situ RT-PCR study. Int J Exp Pathol., 83(3), 133-137.

[8] Zardi, E. M., Zardi, D. M., Cacciapaglia, F., Dobrina, A., Amoroso, A., Picardi, A., \& Afeltra, A. (2005). Endothelial dysfunction and activation as an expression of disease: Role of prostacyclin analogs. International Immunopharmacolocgy, 5, 437-459.

[9] Majed, F., Nafees, S., Rashid, S., Ali, N., Hasan, S. K., Ali, R., Shahid, A., \& Sultana, S., (2015). Terminalia chebula attenuates DMBA/croton oil-induced oxidative stress and inflammation in swiss albino mouse skin. Toxicol Int., 22(1), 21-29.

[10] Ajith, T. A., \& Janardhanan, K. K. (2011). Phellinus rimosus (Berk.) pilat attenuates 7,12-dimethylbenz[a] anthracene induced and croton oil promoted skin papilloma formation in mice. J Exp Ther Oncol., 9(3), 207-215.

[11] Jones, C. L. A. (2000). Herbal aids for cancer. Nutrition Science News dalam Chiro.org.

[12] Surh, Y., (2003). Cancer chemoprevention with dietary phytochemicals. Nature Revs., 3., 768-780.

[13] Nickavar, B., Mojab, F., Javidnia, K., \& Amoli, M. A., (2003). Chemical composition of the fixed and volatile oils of Nigella sativa L. from Iran. J. Naturforsch, 58(9-10), 629-631.

[14] Salem, M. L., \& Hossain, M. S. (2000). Protective effect of black seed oil from Nigella sativa against murine cytomegalovirus infection. Int. J. Pharmacol. 22(9), 729-740.

[15] Sayed, I., \& Fukushima, S., (2003). Chemopreventive potential of volatile oil from black cumin (Nigella sativa L) seeds against rat colon carcinogenesis. J. of Nutrit and Cancer, 45(2), 195-202.

[16] Mousa, D., Dilsiz, N., \& Gumushan, H. (2004). Antitumor activity of an ethanol extract of Nigella sativa seeds. Biologia-Bratislava, 59(6), 735-740.

[17] Randhawa, M. A., \& Al-Ghamdi, M. S. (2002). A review of the pharmaco-therapeutic effects of Nigella sativa. Pakistan J. Med. Res., 41(2).

[18] Iddalmadeniya, S. S., Thabrew, M. L., Wickramasinghe, S. M. D. N., Ratnatunge, N., \& Thammitiyagodage, M. G. (2006). A long-term investigation of the anti-hepatocarcinogenic potential of an indigenous medicine comprised of Nigella sativa, Hemidesmus indicus and Smilax gabra. J.Carcinog, 8(1), 6.

[19] Iddalmadeniya, S. S., Thabrew, M. L., Wickramasinghe, S. M. D. N., Ratnatunge, N., \& Thammitiyagodage, M. G. (2003). Potection against diethylnitrosoamine-induced hepatocarcinogenesis by an indegius medicine compromised comprised of Nigella sativa, Hemidesmus indicus and Smilax gabra. J.Carcinog, $2(1), 6$.

[20] Ghamdi, M. S. (2001). The antiinflamator, analgesic and antipyretic activity of Nigella sativa. Departemen of Pharmacology King Faisal University Collage of Medicine.

[21] Akrom, W. A., \& Djannah, S. N. (2007). Effect of the ethanolic extract of Nigella sativa on phagocytosis activity of macrophage male swiss mice during infection of Listeria monocytogenes. Proceedings of the 4th International Eijkman Conference.

[22] Chen, Y. K., Hsue, S. S., \& Lin, L. M. (2003). Correlation between inducible nitric oxide synthase and p53 expression for DMBA-induced hamster buccal-pouch carcinomas. Oral Dis., 9(5), 227-34.

[23] Fujita, S., Masago, K., Hatachi, Y., Fukuhara, A., Hata, A., Kaji, R., Kim, Y. H., Mio, T., Mishima, M., \& Katakami, N. (2010). Genetic polymorphisms in the endothelial nitric oxide synthase gene correlate with overall survival in advanced non-small-cell lung cancer patients treated with platinum-based doublet chemotherapy. BMC Med Genet, 11, 167.

[24] Badary, O. A., Abd-Ellah, M. F., El-Mahdy, M. A., Salama, S. A., \& Hamada, F. M. (2007). Anticlastogenic activity of thymoquinone against benzo(a)pyrene in mice. Food Chem Toxicol, 45(1), 88-92. 
[25] Badary, O. A., Al-Shabanah, O. A., Nagi, M. N., Al-Rikabi, A. C., \& Elmazar, M. M, (1999). Inhibition of benzo(a)pyrene-induced forestomach carcinogenesis in mice by thymoquinone. Eur J Cancer Prev., 8(5), 435-40

[26] Van, R. C. (2001). Nitric oxide and T helper cell immunity. International Immunopharmacology, 1, 1491-500.

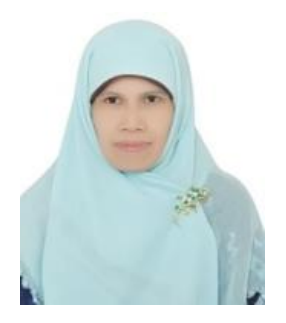

Titiek Hidayati M. Kes was born in Yogyakarta, on September 8, 1968. She is lecturer in the Faculty of Medicine and Health Sciences Universitas Muhammadiyah Yogyakarta (UMY). She is in the Departement of Epidemiology, Community and Family Medicine. Her research interests are Epidemiology, tobacco, environment, public health and degenerative disease.

She has finished her Ph.D program from Medical collage of Gadjah Mada University, Yogyakarta. Her dissertation is about translational research of CKD public genomic.

She served as secretary of the research ethics committees at their institution and member of medical doctor Indonesian association. 